\title{
ATR-FTIR as a potential tool for controlling high quality vinegar categories
}

\author{
Rocío Ríos-Reina $^{\text {a }}$, Raquel M. Callejón ${ }^{\mathrm{a}}$, Celia Oliver-Pozo ${ }^{\mathrm{b}}$, José M. Amigo ${ }^{\mathrm{c}}$, Diego L. García-González ${ }^{\mathrm{b}, *}$ \\ a Área de Nutrición y Bromatología, Facultad de Farmacia, Universidad de Sevilla, C/P. García González n², E-41012, Sevilla, Spain \\ ${ }^{\mathrm{b}}$ Instituto de la Grasa (CSIC), Campus Universidad Pablo de Olavide, Building 46, Ctra. de Utrera, km. 1, E-41013, Sevilla, Spain \\ Spectroscopy and Chemometrics Group, Department of Food Sciences, Faculty of Science, University of Copenhagen, Rolighedsvej 30, Frederiksberg CDK-1958, Denmark
}

\section{A R T I C L E I N F O}

Article history:

Received 20 December 2016

Received in revised form 23 February

2017

Accepted 27 February 2017

Available online $\mathrm{xxx}$

\section{Keywords}

Wine vinegars

Protected Designation of Origin

ATR-FTIR

PCA

Authentication

\section{A B S T R A C T}

Characterization of wine vinegars qualified with a Protected Designation of Origin (PDO) is crucial to certify their quality and authenticity. Spectroscopic techniques as Fourier transform mid infrared spectroscopy (FTIR) with Attenuated Total Reflectance (ATR) has been applied to investigate its potential as a rapid, cost-effective and non-destructive tool for characterizing different categories of high-quality vinegars. Spectra from 67 wine vinegars belonging to the PDOs "Vinagre de Jerez" and "Vinagre Condado de Huelva", including their different established categories, were analyzed in the $4000-600 \mathrm{~cm}^{-1}$ infrared region. Changes associated to categories were observed in the region $1800-900 \mathrm{~cm}^{-1}$. These changes were assigned to certain compounds that increase during aging (e.g. acetic acids, alcohols, esters) or are characteristic of Pedro Ximenez category (e.g. sugars, furfural). Principal component analysis carried out on the most relevant spectral features, revealed that aging of vinegars clearly affect the ATR-FTIR spectra obtained in each PDO.

(C) 2016 Published by Elsevier Ltd.

\section{Introduction}

Vinegar is a product obtained by a double fermentation process (alcoholic and acetous fermentation or acetification) by using a wide variety of methods and different raw materials (wine, honey, cider, etc.). In the past, vinegar was considered as a secondary product in the family of fermented products and lacked of any recognized quality standard. Nowadays, vinegar is considered as a necessary product in households all over the world and many consumers regard it as high quality product.

Wine vinegar is the most commonly used vinegar in Mediterranean countries and Central Europe. It is the result of the conversion of sugars from grape juice into ethanol by yeast and the subsequent oxidation of the ethanol by acetic acid bacteria (Ordóñez, Callejón, Morales, \& García-Parrilla, 2013). The wine vinegars available in the market differ in raw materials and production process. Concerning the latter vinegars can be produced by either a quick acetification system or a slow traditional process (De la Haba, Arias, Ramírez, López, \& Sánchez, 2014). The time and type of aging (in different kinds of woods) are other sources of variability and they greatly affect the vinegar quality. Due to these processes, chemical modifications related with aging and with the microbiological activity occur and they provide specific and singular properties to the final product, being highly appreciated by consumers (Marrufo-Curtido et al., 2012).

Some wine vinegars are traditionally linked to a certain geographical area, and they are protected by the European Union with a legal

\footnotetext{
* Corresponding author.

Email address: dlgarcia@ig.csic.es (D.L. García-González)
}

framework that provides the category of "Protected Designation of Origin" (PDO). A product with a PDO registration means that it is produced, processed and prepared in a given geographical area using a recognized know-how (Council Regulation (EC) 510/2006). Consequently, a PDO registration provides an additional protection of consumers against falsifications and it guarantees some specifications related to their chemical and sensory features (Chinnici et al., 2009).

The production of wine vinegar in Spain is centered in Andalusia (Southern Spain). Andalusia is a region traditionally associated to wine culture where wine vinegars have been protected by three different PDOs because of their unique characteristics: "Vinagre de Jerez" (also known as "Sherry wine vinegar"), "Vinagre Condado de Huelva" and recently "Vinagre Montilla-Moriles". The first two PDOs are already well established and widely commercialized whereas "Vinagre Montilla-Moriles" was just granted its PDO status in 2015 (EU 2015/48) and their vinegars are starting to appear on the market. Furthermore, within each PDO, there are different categories according to their aging time and type in wood barrels. The high quality of these PDOs are the consequence of the raw material (e.g. grape variety, origin), the wooden cask used (e.g. American Oak casks) and the methods of aging. Aging procedures in these PDOs comprises the "criaderas y solera" (also called dynamic aging system) and "añada" (also called static system) systems. The vinegar in the first system is aged in different butts in which aged and young vinegars are sequentially mixed, while the vinegar in the second system is aged in a single butt without mixing with other vinegars.

The regulation on PDO "Vinagre de Jerez" (BOJA, 2008a) describe three categories according to aging time in oak barrels by the dynamic system "criaderas y solera": "Vinagre de Jerez" (aged in wood at least 6 months), "Vinagre de Jerez Reserva" (with a mini- 
mum aging time of 2 years.), "Vinagre de Jerez Gran Reserva" (aged for 10 or more years). This regulation also describes semi-sweet categories (i.e. "Pedro Ximenez", "Moscatel").

The regulation on PDO "Vinagre Condado de Huelva" (BOJA, 2008b) also establishes the following categories: "Vinagre Condado de Huelva" (no aging), "Vinagre Viejo Condado de Huelva Solera" (aged at least 6 months), "Vinagre Viejo Condado de Huelva Reserva" (aged at least 2 years), all aged by the system "criaderas y solera". Furthermore, there is one more category named "Vinagre Viejo Condado de Huelva Añada" aged at least 3 years but in static aging system.

These vinegars have high prices in the market due to their high quality, the long aging time and hence, the high cost of their production. That explains that these products are vulnerable to fraud (Callejón et al., 2012; Sáiz-Abajo, González-Sáiz, \& Pizarro, 2004) and new tools are required to fight against falsification or mislabeling. Furthermore, the growing consumer demand and the increasing diversity of wine vinegars has raised a need to characterize them and to provide an adequate quality control to defend their identity (Cerezo et al., 2008; Liu, He, \& Wang, 2008; Marrufo-Curtido et al., 2012). Different sensory and physicochemical techniques such as gas-chromatography-mass spectrometry (GC-MS), atomic absorption spectrometry or high-performance liquid chromatography (HPLC) have been used to characterize vinegars (Cirlini, Caligiani, Palla, \& Palla, 2011; Natera, Castro, De Valme García-Moreno, Hernández, \& García-Barroso, 2003). However, these techniques are often expensive and time-consuming. Rapid methods based on non-targeted technique can provide a solution for food authentication (Baeten \& Dardenne, 2002). In particular, Fourier transform infrared spectroscopy (FTIR) has become an important tool for quantitative analysis (Rodriguez-Saona \& Allendorf, 2011). FTIR combined with chemometrics has gained wide acceptance in the identification of chemical compounds in foods for authenticity and classification purposes (Grassi, Amigo, Lyndgaard, Foschino, \& Casiraghi, 2014; Moros, Iñón, Garrigues, \& de la Guardia, 2008; Regmi, Palma, \& Barroso, 2012; Tay, Singh, Krishnan, \& Gore, 2002; Van de Voort, Ghetler, García-González, \& $\mathrm{Li}, 2008)$.

The use of an accessory of Attenuated Total Reflectance (ATR) in FTIR studies allows the direct analysis of liquids in a simple and non-destructive manner with enough sensitivity (Gouvinhas, de Almeida, Carvalho, Machado, \& Barros, 2015; Versari, Parpinello, Chinnici, \& Meglioli, 2011). Thus, ATR-FTIR has proven to be an appropriate method for the authentication of several liquid foods such as vinegar (Dong, Zheng, Jiao, Lang, \& Zhao, 2016; Guerrero, Mejías, Marín, Lovillo, \& Barroso, 2010), olive oil, wine, milk or honey (Bendini et al., 2007; Bevin, Fergusson, Perry, Janik, \& Cozzolino, 2006; Gouvinhas et al., 2015; Kelly, Petisco, \& Downey, 2006; Tarantilis, Troianou, Pappas, Kotseridis, \& Polissiou, 2008; Tena, Aparicio-Ruiz, \& García-González, 2014). Scarce studies have been carried out in the characterization of vinegars belonging to PDOs and with different aging times, although some studies already pointed out the utility of different spectroscopic techniques (e.g. near infrared and fluorescence spectroscopy) in vinegar studies (De la Haba, Arias, Ram, í, rez, L, ó, pez, S, á, \& nchez, 2014; Callejón et al., 2012).

The aim of this work was to study the potential of ATR-FTIR for the characterization of wine vinegar categories (aged and sweet) established in two Andalusian PDOs ("Vinagre de Jerez" and "Vinagre Condado de Huelva"). For this purpose, the most relevant spectral bands were identified and the information that they provided were assessed in terms of chemical assignment and vinegar characteristics. Principal component analysis (PCA) was used as unsupervised method in order to explore and compare the data structure and to help in the interpretation of ATR-FTIR analysis.

\section{Materials and methods}

\subsection{Samples}

Sixty-seven wine vinegar samples belonging to different categories registered as Protected Designation of Origin, named "Vinagre de Jerez" and "Vinagre Condado de Huelva", were collected from different wineries of Andalusia (Spain). Samples were divided as follows: 36 "Vinagre de Jerez" and 31 "Vinagre Condado de Huelva" including samples of each established category (Table 1).

\subsection{Chemicals}

Acetic acid was obtained from Merck (Madrid, Spain), and it was of analytical quality. Water was obtained from a Milli-Q purification system (Millipore, USA).

\subsection{ATR-FTIR spectroscopy analysis}

Spectral data were collected on a Bruker Vertex 70 FTIR spectrometer equipped with a DGTS detector (Bruker Optics, Ettlingen, Germany). The sampling station was equipped with an overhead and detachable multi-reflection attenuated total reflectance accessory (ATR, six bounces, Specac, Orpington, U.K.). This accessory consists on a $45^{\circ}$ angle $\mathrm{ZnSe}$ crystal mounted in a shallow channel for the sample. Each spectrum was recorded at the same temperature $\left(22^{\circ} \mathrm{C}\right)$ in the region of 4000-600 $\mathrm{cm}^{-1}$ by an average of 50 scans at a resolution of $4 \mathrm{~cm}^{-1}$. Before scanning each sample, a background spectrum was taken with an empty ATR crystal and recorded in the computer. Each sample $(250 \mu \mathrm{L})$ was spread uniformly through the ATR crystal using a micropipette. After the analysis, the ATR crystal was thoroughly cleaned to eliminate the presence of vinegar residues between measurements and then wiped with cotton. Spectra were examined using OPUS version 7.0 (Bruker Optics, Ettlingen, Germany) and manipulated with OMNIC software. Each sample was analyzed in triplicate.

\subsection{Data analysis}

Data processing and statistical analysis was performed with MATLAB version 8.4.0.150421 (R2014b) and PLS-toolbox version 7.0.2 (Eigenvector Research Inc., Manson, WA). Different preprocessing methods were studied prior to PCA including standard normal variate (SNV), first and second derivative. Moreover, the spectra were properly normalized by mean centering after preprocessing. After some trials and computations, preprocessing was found not to be necessary. Therefore, the raw spectra were just normalized by mean centering.

Table 1

Wine vinegar samples analyzed in this study.

\begin{tabular}{lllll}
\hline $\begin{array}{l}\text { Protected Designation of } \\
\text { Origin (PDO) }\end{array}$ & Categories & code & $\begin{array}{l}\text { Aging time } \\
\text { (months) }\end{array}$ & $\mathrm{n}$ \\
\hline "Vinagre de Jerez" & $\begin{array}{l}\text { "Vinagre de } \\
\text { Jerez" }\end{array}$ & JCR & $\geq 6$ & 15 \\
& $\begin{array}{l}\text { "Reserva" } \\
\text { "Gran Reserva" }\end{array}$ & JRE & $\geq 24$ & 15 \\
& JGR & $\geq 120$ & 3 \\
"Vedro Ximenez" & JPX & - & 3 \\
& "Condado de & CSC & 0 & 10 \\
& $\begin{array}{l}\text { Huelva" } \\
\text { "Viejo Solera" }\end{array}$ & CSO & $\geq 6$ & 7 \\
& "Viejo Reserva" & CRE & $\geq 24$ & 10 \\
& "Viejo Añada" & CAN & $\geq 36$ & 4 \\
\hline
\end{tabular}


Principal component analysis (PCA) was applied to the $1500-900 \mathrm{~cm}^{-1}$ spectral region of the total of samples in triplicate in order to explore the data structure and to identify the main sources of variability in the spectra. Full cross validation (leave-one sample-out) was applied, understanding as sample all the analytical replicates of the same sample. Factor loadings for each principal component were used to assess about the relative importance of each wavenumber and the correlation of them with specific compositional properties according to their category.

\section{Results and discussion}

\subsection{Interpretation of ATR-FTIR wine vinegar spectra}

The first step in this work was to identify the most remarkable bands related to the major compounds that characterize wine vinegar samples. Fig. 1 shows the ATR-FTIR spectra of some analyzed vinegars. For a comparative purpose, a spectrum of Millipore Q-purified water is shown, as well as a spectrum of a mixture of pure acetic acid and water. In the first one (Fig. 1, spectrum A; Table 2 ), the intense bands detected in the regions of $3800-2790 \mathrm{~cm}^{-1}$ and $1685-1550 \mathrm{~cm}^{-1}$ were mainly assigned to $-\mathrm{OH}$ groups of water. The ATR-FTIR spectra of a standard of acetic acid diluted in water (Fig. 1, spectrum B) showed the presence of three new bands: one at $\sim 1711 \mathrm{~cm}^{-1}$ assigned to the $\mathrm{C}=\mathrm{O}$ group of acetic acid, and two bands near $\sim 1410$ and $\sim 1290 \mathrm{~cm}^{-1}$ explained by $\mathrm{C}-\mathrm{O}$ stretching and $\mathrm{C}-\mathrm{O}-\mathrm{H}$ in-plane bending respectively (Moros et al., 2008; Silva, Feliciano, Boas, \& Bronze, 2014; Tarantilis et al., 2008; Versari et al., 2011). Acetic acid also absorbs at $3800-2790 \mathrm{~cm}^{-1}$ due to $\mathrm{C}-$ $\mathrm{H}$ and $\mathrm{O}-\mathrm{H}$ stretching, although it is not observable in the spectrum for being overlapped by $\mathrm{O}-\mathrm{H}$ absorption of water (Moros et al., 2008). Concerning the spectra of vinegar samples (spectra C, D and $\mathrm{E}$ in Fig. 1), all the bands associated to water and acetic acid were the most intense ones. Other minor bands were characteristics of some specific kinds of vinegars (Table 2). Thus, the region at
$1500-900 \mathrm{~cm}^{-1}$ also showed spectral bands assigned to complex interacting vibrations, resulting in a unique fingerprint for each vinegar.

Fig. 2 shows two ATR-FTIR spectra corresponding to an aged wine vinegar (Reserva category) and a "Pedro Ximenez" wine vinegar, both of them from PDO "Vinagre de Jerez". In addition to the bands assigned to water and acetic acid (spectral bands 1 to 6), the region $1500-900 \mathrm{~cm}^{-1}$ shows other absorption bands assigned to $\mathrm{C}$ $-\mathrm{O}, \mathrm{C}-\mathrm{C}, \mathrm{C}-\mathrm{H}, \mathrm{C}-\mathrm{N}, \mathrm{N}-\mathrm{H}$ and $\mathrm{C}=\mathrm{O}$ groups (Stuart, 2004) (Table 2). These bands were produced by the presence of carboxylic acids, aldehydes, esters, ethers, alcohols and phenols and some nitrogen compounds presented in wine vinegar (Callejón et al., 2008b; Stuart, 2004). All these chemical groups have been identified in vinegars and they have an impact on quality properties (Callejón, Morales, Silva Ferreira, \& Troncoso, 2008a). Fig. 2.A and 2.B shows the average spectra (region $1160-900 \mathrm{~cm}^{-1}$ ) of the aged categories for "Vinagre de Jerez" and "Vinagre Condado de Huelva" respectively. Peaks 7,8 and $9\left(\sim 1085, \sim 1045\right.$ and $\left.1015 \mathrm{~cm}^{-1}\right)$ were assigned to alcohol compounds, aldehydes, and some esters and ethers as well as acids (Duarte, Barros, Almeida, Spraul, \& Gil, 2004; Nieuwoudt, Prior, Pretorius, Manley, \& Bauer, 2004; Versari et al., 2011). These bands were related to the aforementioned chemical compounds whose concentration increase during aging (Morales, Tesfaye, García-Parrilla, Casas, \& Troncoso, 2001; Morales, Tesfaye, García-Parrilla, Casas, \& Troncoso, 2002; Tesfaye, Morales, García-Parrilla, \& Troncoso, 2002) being responsible for the variations in the absorbance intensities that are shown in the region $1160-900 \mathrm{~cm}^{-1}$ (Fig. 2.A and 2.B). Vinegars with longer aging period, such as "Vinagre de Jerez Gran Reserva" (JGR), "Vinagre de Jerez Reserva" (JRE), "Vinagre Condado de Huelva Reserva" (CRE), and "Vinagre Condado de Huelva Añada" (CAN), showed an increase in the intensity of the band at $\sim 1045 \mathrm{~cm}^{-1}$ (band 8) and a slight increment at $\sim 1085 \mathrm{~cm}^{-1}$ (band 7). These two spectral bands were explained by the presence of alcoholic and ester compounds (mainly ethanol and ethyl acetate), whose functional groups $(\mathrm{C}-\mathrm{O})$ absorb at this range of the spectrum (Duarte et al., 2004; Stuart, 2004). The spectral differences observed in aged categories agree with the fact that aging

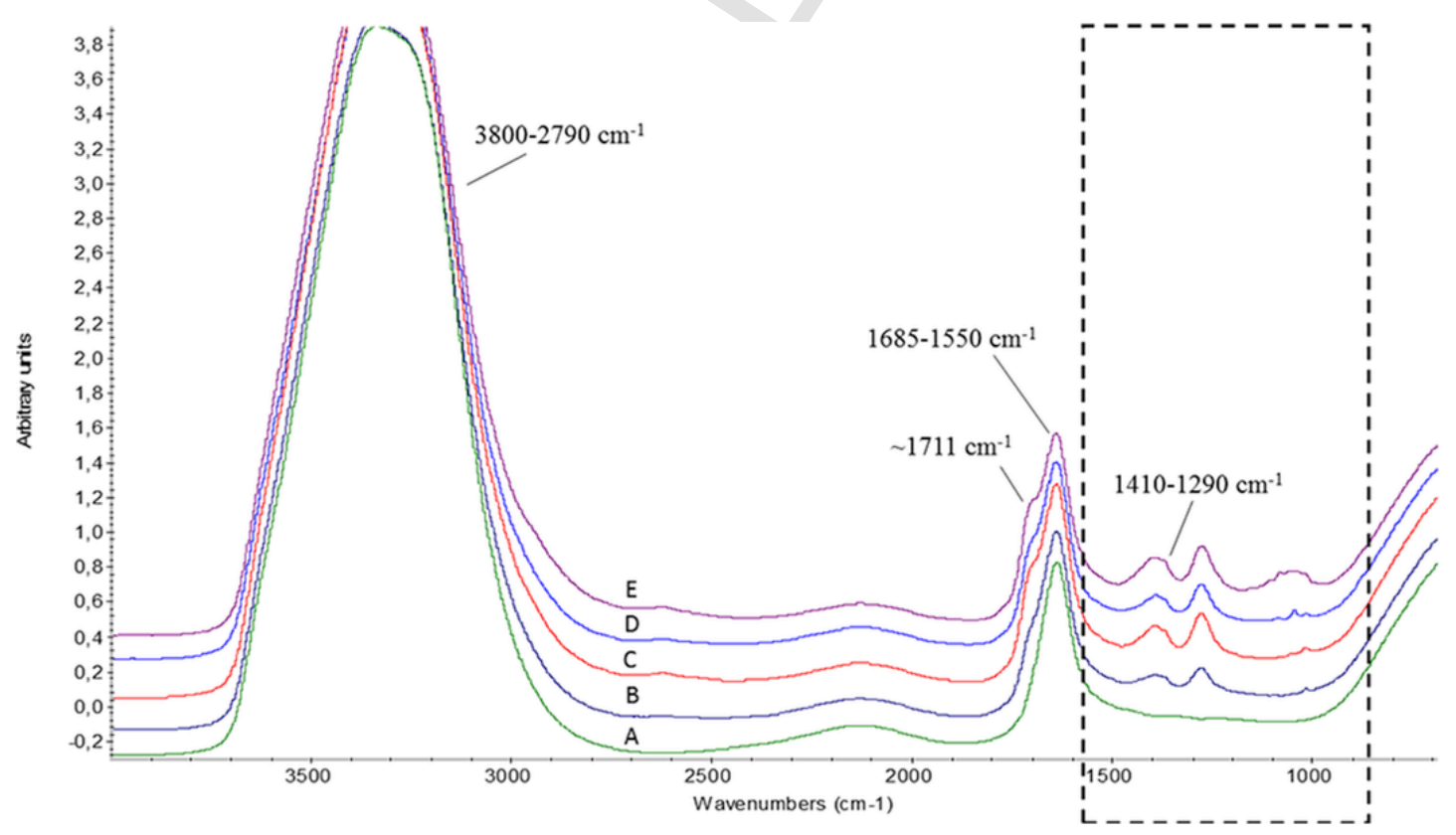

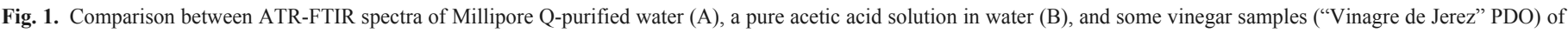
different categories: "Crianza" (C), "Reserva" (D) and "Pedro Ximenez" (E). 
Table 2

Chemical assignment of the bands observed in the ATR-FTIR spectra of wine vinegars (Stuart, 2004; Aldrich library; Sigma Sample library).

\begin{tabular}{|c|c|c|}
\hline Compounds & Principal Group Identified & $\begin{array}{l}\text { Spectral Region } \\
\left(\mathrm{cm}^{-1}\right)\end{array}$ \\
\hline Water & $\mathrm{O}-\mathrm{H}$ band & $\begin{array}{r}3800-2790 \\
1685-1550\end{array}$ \\
\hline Acetic acid & $\begin{array}{l}\mathrm{C}-\mathrm{H}, \mathrm{C}=\mathrm{O}, \mathrm{C}-\mathrm{O} \\
\text { stretching and } \mathrm{C}-\mathrm{O}-\mathrm{H} \\
\text { in-plane bending }\end{array}$ & $\begin{array}{c}3800-2790 \\
1800-1680 \\
1475-1230\end{array}$ \\
\hline Acids & $\mathrm{C}-\mathrm{O}$ stretching & $1300-1000$ \\
\hline Ethanol, Glycerol & $\mathrm{C}-\mathrm{O}$ stretching & $1100-1000$ \\
\hline $\begin{array}{l}\text { Alcohols (e.g. 1-hexanol, } \\
\text { 2-methyl-1-butanol) }\end{array}$ & $\begin{array}{l}\mathrm{O}-\mathrm{H} \text { stretching band, } \mathrm{C}- \\
\mathrm{O} \text { stretching }\end{array}$ & $3600 ; 1575-900$ \\
\hline $\begin{array}{l}\text { Esters (e.g. ethyl acetate, } \\
\text { isoamyl acetate, ethyl } \\
\text { propanoate) }\end{array}$ & $\begin{array}{l}\text { Aliphatic and aromatic } \mathrm{C}- \\
\mathrm{O} \text { and } \mathrm{C}=\mathrm{O} \text { stretching }\end{array}$ & $1700-1100$ \\
\hline Sugars (fructose, glucose) & $\mathrm{O}-\mathrm{H},-\mathrm{CH}_{2}$ & $1065-1030$ \\
\hline $\begin{array}{l}\text { Aldehydes (e.g. } \\
\text { Benzaldehyde) }\end{array}$ & $\mathrm{C}=\mathrm{O}$ stretching & $1700-1600$ \\
\hline $\begin{array}{l}\text { Phenols (e.g. guaiacol, } \\
\text { eugenol, 4-ethylphenol) }\end{array}$ & $-\mathrm{C}-\mathrm{O}, \mathrm{O}-\mathrm{H}$ stretching & $1800-900$ \\
\hline Furfurals & $\mathrm{C}=\mathrm{O}, \mathrm{C}=\mathrm{C}$ & $\begin{array}{l}1300-840 \text { and } \\
\sim 1020\end{array}$ \\
\hline
\end{tabular}

promotes several phenomena that affects the chemical composition of vinegars (Callejón, Morales, Silva Ferreira, \& Troncoso, 2008b). The main changes involve water losses through wood pores, increases in acetic acid concentration, extraction of phenolic compounds from wood and formation of aroma compounds, mainly esters (Callejón et al., 2008b; García-Parrilla, Heredia, \& Troncoso, 1999).

Fig. 2 also showed the spectra of a "Pedro Ximenez" vinegar, which is a particular sweet category of PDO "Vinagre de Jerez". Its spectrum showed a singular group of peaks in the region of $1175-1000 \mathrm{~cm}^{-1}$ (band 10, Fig. 2). This kind of vinegar has a high carbohydrate content and they suffer a Maillard reaction that induces the condensation of the reducing carbohydrates (glucose and fructose) and free amino acids producing an appearance of brown pigments and volatile compounds (Casale, Sáiz Abajo, González Sáiz,
Pizarro, \& Forina, 2006). Their characteristic bands in the region of $1175-1000 \mathrm{~cm}^{-1}$ mainly resulted from grape sugars and furfural compounds that are characteristics of these sweet vinegars (Casale et al., 2006). In fact, in previous studies the spectra of glucose and fructose showed a major peak at 1034 and $1062 \mathrm{~cm}^{-1}$ respectively (Sivakesava \& Irudayaraj, 2000) and furfural at $1020 \mathrm{~cm}^{-1}$ and $1300-840 \mathrm{~cm}^{-1}$ (Dong et al., 2016) (Table 2).

\subsection{Principal component analysis}

In order to check the ability of the aforementioned bands to characterize Andalusian PDO vinegars and to find out if the spectral profile of these wine vinegars may be consistently correlated with specific compositional properties and/or sample aging, principal component analysis (PCA) was performed. PCA was used to detect groups of samples, outliers and to provide a visual representation of the relationships within the samples and between them (scores) and the variables (loadings). PCA was carried out with the spectral region $1500-900 \mathrm{~cm}^{-1}$, previously preprocessed by mean centering, of the total of samples by triplicate from each PDO.

\subsubsection{PDO "Vinagre de Jerez"}

The two first principal components (PCs) of the different aged categories and Pedro Ximenez vinegars included in the "Vinagre de Jerez" PDO explained $97.33 \%$ of the total variance. Fig. 3 shows the scores and loadings plots in the plane defined by PC1 and PC2. PC1 allowed the separation of the "Pedro Ximenez" samples. Additionally, samples were distributed along PC1 according to their aging (Fig. 3-A): "Gran Reserva" with positive values of PC1; "Crianza", with negative values of $\mathrm{PC} 1$; and "Reserva" with both negative and positive values of $\mathrm{PC} 1$. This difference is mainly due to the wide range of aging time in these vinegars (from 6 months to $>10$ years). Nonetheless, some overlapping was observed in the PCA scores plot since aging is a factor that develops with time. Thus, "Reserva" vinegars (2-10 years) that were aged for slightly more than 2 years were observed close to "Crianza" category (6 months-2 years). Similar re-

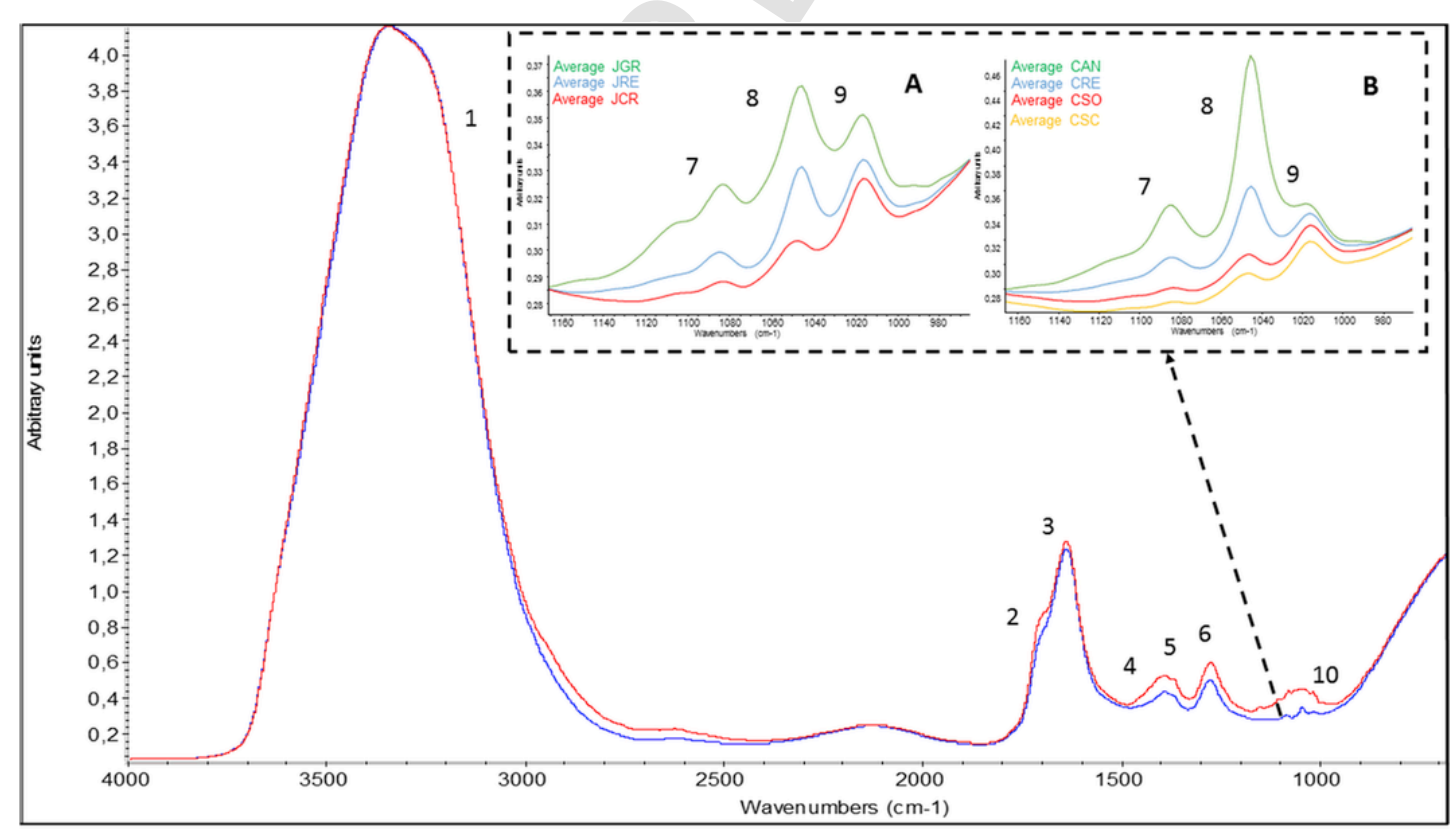

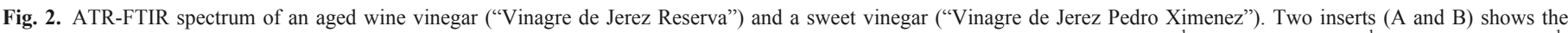

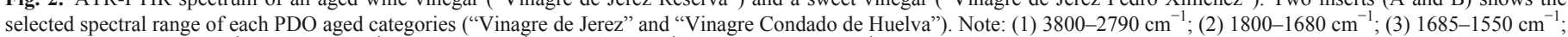
(4) (5) (6) $1475-1230 \mathrm{~cm}^{-1}$ (7) $\sim 1085 \mathrm{~cm}^{-1}$; (8) 1045 $\mathrm{cm}^{-1}$; (9) $1015 \mathrm{~cm}^{-1}$; (10) $1175-1000 \mathrm{~cm}^{-1}$. The acronyms for the different vinegar categories are defined in Table 1. 

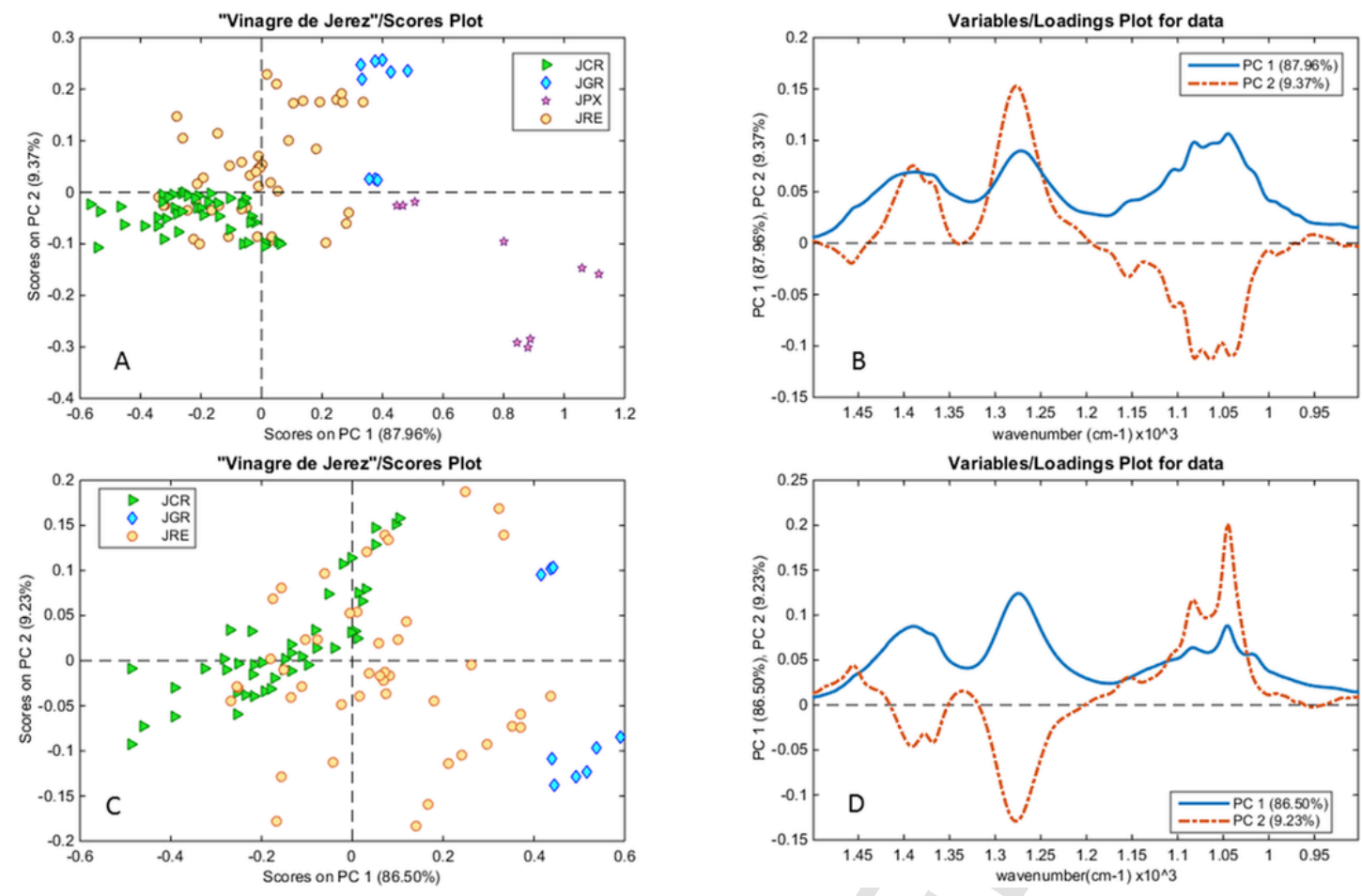

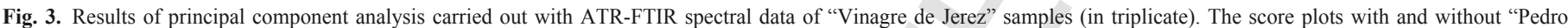

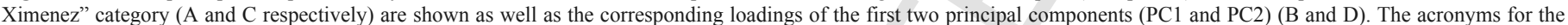
different vinegar categories are defined in Table 1.

sults were obtained in a previous work (Callejón et al., 2012) in which vinegars of different aging were analyzed by fluorescence spectroscopy. The loadings plot corresponding to the two PCs with higher amount of total variance, PC1 and PC2 (Fig. 3.B), shows that two specific regions of the spectra had more importance in the model $\left(1175-1000 \mathrm{~cm}^{-1}\right.$ and $\left.1475-1230 \mathrm{~cm}^{-1}\right)$. PC1 $(87.96 \%$ of the total variance) was mainly associated with positive values to the spectral region of $1175-1000 \mathrm{~cm}^{-1}$. This region was ascribed to the samples with higher amount of sugars from grape-juice in their composition that was characteristic of "Pedro Ximenez" vinegars. These loadings for PC1 explained that Pedro Ximenez samples were separated from the rest of vinegars. In addition to this region, PC2 loadings showed positive values at the absorption bands characteristics of acetic acid (1475-1230 $\mathrm{cm}^{-1}$ ) explaining that the majority of wine vinegar samples with more aging time were located in the positive side of PC2 (e.g. all "Gran Reserva" and many "Reserva" samples).

Once the Pedro Ximenez samples were explained and showed distinctive spectral characteristics, they were removed from the data in order to carry out a differentiation of the rest of vinegars (aged categories). Scores and loadings of the first two PCs are shown in Fig. 3.C and 3.D, accounting for $95.98 \%$ of the total variability. Once again, two regions of the spectra where highlighted in the loadings plot: $1475-1230 \mathrm{~cm}^{-1}$ and the two peaks at $\sim 1085 \mathrm{~cm}^{-1}$ and $\sim 1045 \mathrm{~cm}^{-1}$. The highest contributions corresponded to the bands assigned to acetic acid and alcoholic, ethers and esters compounds respectively, indicating the relationship previously described (Fig. 2) between aging time and the increase of these compounds. The projection onto the reduced space spanned by the PCs allowed the separation of "Gran Reserva" and "Crianza" categories (with positive and negative values for PC1 respectively) in the score plot (Fig. 3.C), while the samples of the "Reserva" category were distributed be- tween the two other groups, showing the importance of the aging in the spectral characteristics.

\subsubsection{PDO "Vinagre Condado de Huelva"}

A PCA was carried out with samples of all the categories of wine vinegar commercialized by "Vinagre Condado de Huelva" PDO (Fig. 4). The results obtained were similar to the PCA carried out for "Vinagre de Jerez" samples. Fig. 4 shows the scores and loadings plots of the first two principal components (PCs), accounting for $97.08 \%$ of the total variability. The score plot (Fig. 4.A) shows that PC1 explained most of the variability $(81.39 \%)$ and allowed the differentiation between two groups: the less aged vinegars ("Vinagre Condado de Huelva") placed in the negative side of PC1, to the most aged vinegars ("Añada" and "Reserva") in the positive side. Moreover, from a conceptual standpoint, it is possible to rather affirm that the aging direction is not only PC1 but it is the diagonal of the PC1 vs PC2 plot, so that more aged vinegars result in a simultaneous increase in the scores along both components. Once again, there was an overlapping of samples belonging to the intermediate category "Solera", aged from 6 months to 2 years, with the category immediately more aged "Reserva", aged for more than 2 years. In regards to the loadings (Fig. 4.B), the highest contributions of PC1 corresponded to the bands assigned to acetic acid $\left(1475-1230 \mathrm{~cm}^{-1}\right)$, and the positive loadings of PC1 and PC2 were assigned to alcoholic, ethers and esters compounds $\left(1085 \mathrm{~cm}^{-1}\right.$ and $\left.1045 \mathrm{~cm}^{-1}\right)$. These highlighted regions confirmed again the relationship between aging time and the intensity of these bands. The loading profile shown in Fig. 4-B were similar to those obtained with the samples from "Vinagre de Jerez" PDO (Fig. 3-D).

These results suggested that FTIR spectra could be used to identify the main differences between the established categories of wine vinegars within each PDO. The "fingerprint" region of vinegar spec- 

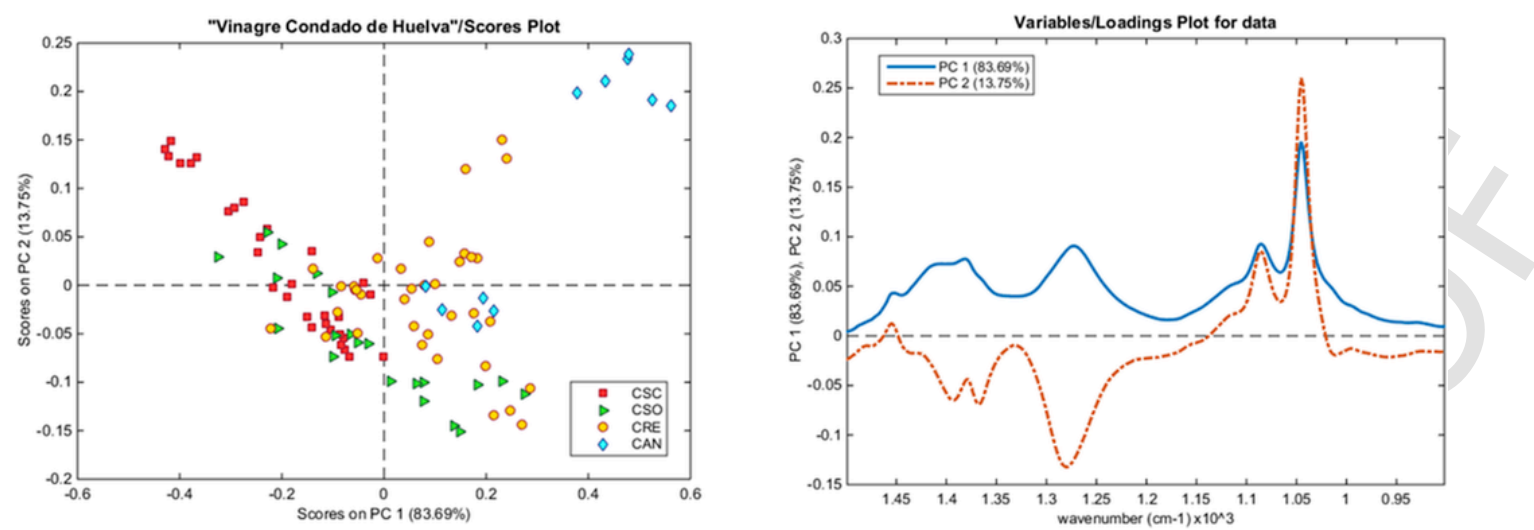

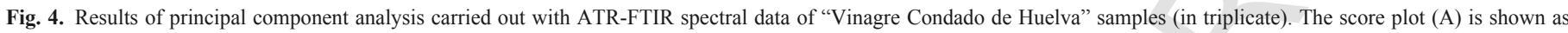
well as the corresponding loadings of the first two principal components (PC1 and PC2) (B). The acronyms for the different vinegar categories are defined in Table 1.

tra has demonstrated to provide important information for characterizing each wine vinegar.

In addition to the differentiation of categories within each PDO, the spectral signals of the two PDOs were included in the same PCA model. In this study, only the categories with the same range of aging ( $>6$ months and $>24$ months) were considered since they are comparable between PDOs (Table 1). Fig. 5.A shows the scores plot of the first two PCs, accounting for $93.98 \%$ of the total variability. The scores showed a clear differentiation between the two PDOs. These results reinforced that wine vinegars produced under the specifications of PDOs have unique quality and characteristics. The spectral loadings responsible for differentiation (Fig. 5.B) were again located in the ranges $1475-1230 \mathrm{~cm}^{-1}$ and $1175-1000 \mathrm{~cm}^{-1}$, already selected in previous PCA models.

\section{Conclusions}

In this study, FTIR proved to be useful for a simple characterization of the established aging categories of high quality wine vinegars protected under PDO. The ability of the spectral bands in distinguishing vinegars by their categories and aging time is mainly based on a series of bands observed in the region of $1500-900 \mathrm{~cm}^{-1}$. These bands provided valuable information about changes related to specific compounds during aging in wood barrels (acetic acid, alcohols, ethers, esters, etc.). Since aging is a continuous variable, the interme- diate categories in aging (e.g. "Reserva") were overlapped with the other categories to some extent, while the spectral data allowed a clear separation of the most and least aged categories. This procedure also allowed characterizing sweet vinegars ("Pedro Ximenez" category) whose spectra were clearly different compared to aged categories, mostly due to bands assigned to sugars and Maillard compounds $\left(1175-1000 \mathrm{~cm}^{-1}\right)$. Furthermore, the unique characteristics of the Spanish PDO wine vinegars, which directly affect the ATR-FTIR spectra, also allowed the differentiation between PDOs.

The advantages of this method (e.g. fast, non-destructive and with no-sample preparation) would allow implementing this measurement as an additional control for PDO councils and producers to assess the category of the different wine vinegars established in each PDO, and to monitor the aging process with a simple and rapid procedure. The chemical assignment of the bands described in this work and the previous knowledge of vinegar composition provided an additional chemical support to FTIR spectroscopy for this application.

\section{Funding}

This work was supported by the "Consejería de Economía, Innovación y Ciencia, Junta de Andalucía" under the project P12-AGR-1601 and by a FPU scholarship of the Ministerio de Educación, Cultura y Deporte.
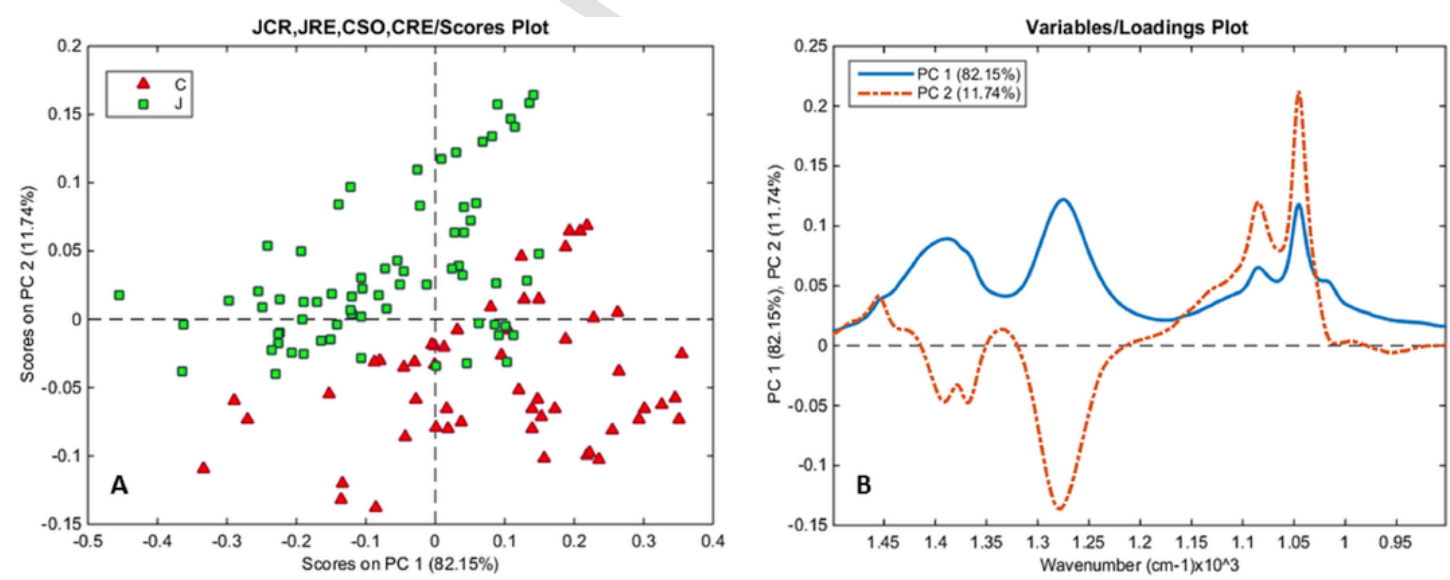

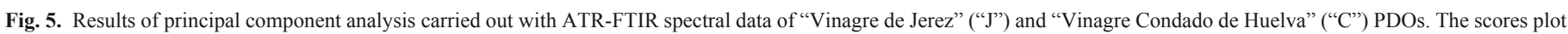
(A) is shown as well as the corresponding loadings of the first two principal components (PC1 and PC2) (B). The acronyms for the vinegar categories are defined in Table 1. 


\section{Acknowledgments}

We would like to thank to the Regulatory Councils of the wine vinegar PDOs for their invaluable help with the acquisition of the samples for this study.

\section{References}

Baeten, V., Dardenne, P., 2002. Spectroscopy: Developments in instrumentation and analysis. Grasas y Aceites 53, 45-63.

Bendini, A., Cerretani, L., Di Virgilio, F., Belloni, P., Bonoli-Carbognin, M., Lercker, G., 2007. Preliminary evaluation of the application of the ftir spectroscopy to control the geographic origin and quality of virgin olive oils. Journal of Food Quality $30,424-437$.

Bevin, C.J., Fergusson, A.J., Perry, W.B., Janik, L.J., Cozzolino, D., 2006. Development of a rapid "fingerprinting" system for wine authenticity by mid-infrared spectroscopy. Journal of Agricultural and Food Chemistry 54, 9713-9718.

BOJA, 2008a. Inscripción de la Denominación de Origen Protegida "Vinagre del Condado de Huelva". In: Boletín Oficial de la Junta de Andalucía de 16 de septiembre de 2008, Vol. 184, pp. 35-40.

BOJA, 2008b. Inscripción de la Denominación de Origen Protegida "Vinagre de Jerez". In: Boletín Oficial de la Junta de Andalucía de 16 de septiembre de 2008, Vol. 184, pp. 29-35.

Callejón, R.M., Amigo, J.M., Pairo, E., Garmón, S., Ocaña, J.A., Morales, M.L., 2012 Classification of Sherry vinegars by combining multidimensional fluorescence, parafac and different classification approaches. Talanta 88, 456-462.

Callejón, R.M., Morales, M.L., Silva Ferreira, A.C., Troncoso, A.M., 2008a. Defining the typical aroma of Sherry vinegar: Sensory and chemical approach. Journal of Agricultural and Food Chemistry 56, 8086-8095.

Callejón, R.M., Tesfaye, W., Torija, M.J., Mas, A., Troncoso, A.M., Morales, M.L., 2008b. HPLC determination of amino acids with AQC derivatization in vinegars along submerged and surface acetifications and its relation to the microbiota. European Food Research and Technology 227, 93-102.

Casale, M., Sáiz Abajo, M.J., González Sáiz, J.M., Pizarro, C., Forina, M., 2006. Study of the aging and oxidation processes of vinegar samples from different origins during storage by near-infrared spectroscopy. Analytica Chimica Acta 557, 360-366.

Cerezo, A.B., Tesfaye, W., Torija, M.J., Mateo, E., García-Parrilla, M.C., Troncoso, A.M., 2008. The phenolic composition of red wine vinegar produced in barrels made from different woods. Food Chemistry 109, 606-615.

Chinnici, F., Guerrero, E.D., Sonni, F., Natali, N., Marín, R.N., Riponi, C., 2009. Gas chromatography-mass spectrometry (GC-MS) characterization of volatile compounds in quality vinegars with protected European geographical indication. Journal of Agricultural and Food Chemistry 57, 4784-4792.

Cirlini, M., Caligiani, A., Palla, L., Palla, G., 2011. HS-SPME/GC-MS and chemometrics for the classification of Balsamic Vinegars of Modena of different maturation and ageing. Food Chemistry 124, 1678-1683.

De la Haba, M.J., Arias, M., Ramírez, P., López, M.I., Sánchez, M.T., 2014. Characterizing and authenticating montilla-moriles PDO vinegars using near infrared reflectance spectroscopy (NIRS) technology. Sensors 14, 3528-3542.

Dong, D., Zheng, W., Jiao, L., Lang, Y., Zhao, X., 2016. Chinese vinegar classification via volatiles using long-optical-path infrared spectroscopy and chemometrics. Food Chemistry 194, 95-100.

Duarte, I.F., Barros, A., Almeida, C., Spraul, M., Gil, A.M., 2004. Multivariate analysis of NMR and FTIR data as a potential tool for the quality control of beer. Journal of Agricultural and Food Chemistry 52, 1031-1038.

García-Parrilla, M.C., Heredia, F.J., Troncoso, A.M., 1999. Sherry wine vinegars: Phenolic composition changes during aging. Food Research International 32, 433-440.

Gouvinhas, I., de Almeida, J.M.M.M., Carvalho, T., Machado, N., Barros, A.I.R.N.A., 2015. Discrimination and characterisation of extra virgin olive oils from three cultivars in different maturation stages using Fourier transform infrared spectroscopy in tandem with chemometrics. Food Chemistry 174, 226-232.

Grassi, S., Amigo, J.M., Lyndgaard, C.B., Foschino, R., Casiraghi, E., 2014. Beer fermentation: Monitoring of process parameters by FT-NIR and multivariate data analysis. Food Chemistry 155, 279-286.

Guerrero, E.D., Mejías, R.C., Marín, R.N., Lovillo, M.P., Barroso, C.G., 2010. A new FT-IR method combined with multivariate analysis for the classification of vinegars from different raw materials and production processes. Journal of the Science of Food and Agriculture 90, 712-718.
Kelly, J.D., Petisco, C., Downey, G., 2006. Application of Fourier transform midinfrared spectroscopy to the discrimination between Irish artisanal honey and such honey adulterated with various sugar syrups. Journal of Agricultural and Food Chemistry 54 (17), 6166-6171.

Liu, F., He, Y., Wang, L., 2008. Determination of effective wavelengths for discrimination of fruit vinegars using near infrared spectroscopy and multivariate analysis. Analytica Chimica Acta 615, 10-17.

Marrufo-Curtido, A., Cejudo-Bastante, M.J., Durán-Guerrero, E., Castro-Mejías, R., Natera-Marín, R., Chinnici, F., et al., 2012. Characterization and differentiation of high quality vinegars by stir bar sorptive extraction coupled to gas chromatography-mass spectrometry (SBSE-GC-MS). LWT - Food Science and Technology $47,332-341$.

Morales, M.L., Tesfaye, W., García-Parrilla, M.C., Casas, J.A., Troncoso, A.M., 2001. Sherry wine vinegar: Physicochemical changes during the acetification process Journal of the Science of Food and Agriculture 81, 611-619.

Morales, M.L., Tesfaye, W., García-Parrilla, M.C., Casas, J.A., Troncoso, A.M., 2002. Evolution of the aroma profile of sherry wine vinegars during an experimental aging in wood. Journal of Agricultural and Food Chemistry 50, 3173-3178.

Moros, J., Iñón, F.A., Garrigues, S., de la Guardia, M., 2008. Determination of vinegar acidity by attenuated total reflectance infrared measurements through the use of second-order absorbance- $\mathrm{pH}$ matrices and parallel factor analysis. Talanta 74, 632-641.

Natera, R., Castro, R., De Valme García-Moreno, M., Hernández, M.J., García-Barroso, C., 2003. Chemometric studies of vinegars from different raw materials and processes of production. Journal of Agricultural and Food Chemistry $51,3345-3351$

Nieuwoudt, H.H., Prior, B.A., Pretorius, I.S., Manley, M., Bauer, F.F., 2004. Principal component analysis applied to Fourier transform infrared spectroscopy for the design of calibration sets for glycerol prediction models in wine and for the detection and classification of outlier samples. Journal of Agricultural and Food Chemistry $52,3726-3735$.

Ordóñez, J.L., Callejón, R.M., Morales, M.L., García-Parrilla, M.C., 2013. A survey of biogenic amines in vinegars. Food Chemistry 141, 2713-2719.

Regmi, U., Palma, M., Barroso, C.G., 2012. Direct determination of organic acids in wine and wine-derived products by Fourier transform infrared (FT-IR) spectroscopy and chemometric techniques. Analytica Chimica Acta 732, 137-144.

Rodriguez-Saona, L.E., Allendorf, M.E., 2011. Use of FTIR for rapid authentication and detection of adulteration of food. Annual Review of Food Science and Technology 2, 467-483.

Sáiz-Abajo, M.J., González-Sáiz, J.M., Pizarro, C., 2004. Classification of wine and alcohol vinegar samples based on near-infrared spectroscopy. Feasibility study on the detection of adulterated vinegar samples. Journal of Agricultural and Food Chemistry 52, 7711-7719.

Silva, S.D., Feliciano, R.P., Boas, L.V., Bronze, M.R., 2014. Application of FTIR-ATR to Moscatel dessert wines for prediction of total phenolic and flavonoid contents and antioxidant capacity. Food Chemistry 150, 489-493.

Sivakesava, S., Irudayaraj, J., 2000. Determination of sugars in aqueous mixture using Mid-Infrared spectroscopy. Applied Engineering in Agriculture 16, 543-550.

Stuart, B.H., 2004. Introduction. In: Infrared Spectroscopy: Fundamentals and applications. John Wiley \& Sons, Ltd, Chichester, UK.

Tarantilis, P.A., Troianou, V.E., Pappas, C.S., Kotseridis, Y.S., Polissiou, M.G., 2008. Differentiation of Greek red wines on the basis of grape variety using attenuated total reflectance Fourier transform infrared spectroscopy. Food Chemistry $111,192-196$

Tay, A., Singh, R.K., Krishnan, S.S., Gore, J.P., 2002. Authentication of olive oil adulterated with vegetable oils using fourier transform infrared spectroscopy. LWT Food Science and Technology 35, 99-103.

Tena, N., Aparicio-Ruiz, R., García-González, D., 2014. Use of polar and nonpolar fractions as additional information sources for studying thermoxidized virgin olive oils by FTIR. Grasas Y Aceites 65 (3), 1-30.

Tesfaye, W., Morales, M.L., García-Parrilla, M.C., Troncoso, A.M., 2002. Evolution of phenolic compounds during an experimental aging in wood of Sherry vinegar. Journal of Agricultural and Food Chemistry 50, 7053-7061.

Van de Voort, F.R., Ghetler, A., García-González, D.L., Li, Y.D., 2008. Perspectives on Quantitative Mid-FTIR spectroscopy in relation to edible oil and lubricant analysis: Evolution and integration of analytical methodologies. Food Analytical Methods 1, 153-163.

Versari, A., Parpinello, G.P., Chinnici, F., Meglioli, G., 2011. Prediction of sensory score of Italian traditional balsamic vinegars of Reggio-Emilia by mid-infrared spectroscopy. Food Chemistry 125, 1345-1350. 